Original Research Paper

\title{
Mengenalkan Urban Farming pada Mahasiswa Untuk Ketahanan Pangan di Masa Pandemi Covid-19 dan Menambah Nilai Ekonomi
}

\author{
Deni Nasir Ahmad ${ }^{1 *}$, Luluk Setyowati ${ }^{2}$ \\ ${ }^{1}$ Pendidikan Matematika, Universitas Indraprasta PGRI, Jakarta Selatan, Indonesia \\ ${ }^{2}$ Pendidikan Fisika, Universitas Indraprasta PGRI Jakarta Selatan, Indonesia
}

https://doi.org/10.29303/jpmpi.v3i2.621

Sitasi: Ahmad, D. N., \& Setyowati, L. (2021). Mengenalkan Urban Farming pada Mahasiswa Untuk Ketahanan Pangan di Masa Pandemi Covid-19 dan Menambah Nilai Ekonomi. Jurnal Pengabdian Magister Pendidikan IPA, 4(1)

\author{
Article history \\ Received: 05 Desember 2020 \\ Revised: 30 Desember 2020 \\ Accepted: 08 Februari 2021 \\ *Corresponding Author: Deni \\ Nasir Ahmad, Pendidikan \\ Matematika, Universitas \\ Indraprasta PGRI, Jakarta \\ Selatan, Indonesia; \\ Email: \\ deninasirahmad@gmail.com
}

\begin{abstract}
Permasalahan ketahanan pangan pada saat ini di Indonesia menjadi permasalahan yang terus dibahas oleh pemerintah. Selanjutnya pada masa pandemik Covid-19 nilai perekonomian masyarakat menurun mengharuskan masyarakat untuk mengambil andil besar dalam ketersediaan kebutuhan secara pribadi pada beberapa komoditas, misalkan cabai, daging ayam, bawang merah dan bawang putih. Urban farming yang berarti bercocok tanam di lingkungan rumah perkotaan dianggap beriringan dengan keinginan masyarakat kota untuk menjalani gaya hidup sehat. Hasil panen dari urban farming lebih menyehatkan lantaran sepenuhnya menerapkan sistem penanaman organik, yang tidak menggunakan pupuk kimia dan pestisida sintesis. Metode dalam melakukan kegiatan yaitu : 1 . Tahap persiapan tim pengabdi sebelum melakukan pengabdian masyarakat yakni pengabdi melihat tingkat kebutuhan mitra, sumber daya yang dapat dimanfaatkan dan penggunaan alat dan bahan yang diperlukan guna memenuhi kebutuhan atas permasalahan yang terjadi pada mitra. 2. Tahap pengabdian, tahap ini tim pengabdi melakukan kegiatan dengan presentasi dan pengenalan urban farming sebagai solusi ketahanan pangan dan nilai ekonomis dengan menggunakan Zoom Meeting guna memberikan informasi secara langsung dengan tetap menjaga kebersihan diri yang dianjurkan pemerintah pada masa pandemik Covid-19. 3. Tahap akhir, evaluasi kegiatan yang telah dilakukan tim pengabdi kepada mitra pengabdi sebagai umpan balik kegiatan. Hasil kegiatan peserta memberikan respon positif dalam setiap kegiatan yang telah dilakukan oleh tim pengabdi yakni peserta banyak memberikan banyak pertanyaan dalam memperoleh informasi yang dibutuhkan. Kesimpulan kegiatan pengabdian yang telah dilakukan oleh tim pengabdi bahwa informasi yang telah diberikan oleh pemateri sangat mengena ke peserta atau sesuai dengan kebutuhan informasi bahkan bagi beberapa peserta menjadikan sebuah ide baru berdasarkan permasalahan yang ada dan menjadikan sebuah produk teknologi dalam pertanian.
\end{abstract}

Keywords: Urban Farming; Covid-19; Ketahanan Pangan.

\section{Pendahuluan}

Permasalahan ketahanan pangan pada saat ini di Indonesia menjadi permasalahan yang terus dibahas oleh pemerintah. Selain ketahanan pangan terjadi permasalahan pada kota besar dimana lahan terbuka pada perumahan dan apartemen yang dijadikan lahan tempat tinggal sudah tidak besar oleh sebab itu perlunya ada teknologi untuk memenuhi perwujudan ketahanan pangan. Hal tersebut menjadi urgensi atau perlu dilakukan 
pertanian kota pada masa sekarang yakni adanya krisis ekonomi menyebabkan keamanan pangan menjadi pertanyaan besar. Keamanan pangan, khususnya bagi masyarakat miskin kota tampaknya akan menjadi isu yang penting di masa depan.
Dalam laporan Kementerian Pertanian dan Kementerian Perdagangan melaporkan hasil stok kebutuhan pangan pada setiap komoditas adalah sebagai berikut (Hirawan dan Akita 2020):

Tabel 1. Perkiraan Stok dan Kebutuhan Pangan Maret-Mei 2020 (dalam ton)

\begin{tabular}{|l|c|c|c|}
\hline \multicolumn{1}{|c|}{ Komoditas } & $\begin{array}{c}\text { Perkiraan Stok Maret- } \\
\text { Mei 2020 }\end{array}$ & $\begin{array}{c}\text { Perkiraan Kebutuhan } \\
\text { Maret-Mei 2020 }\end{array}$ & $\begin{array}{c}\text { Perkiraan Stok } \\
\text { Akhir Mei 2020 }\end{array}$ \\
\hline Beras & 15,9 juta & 7,6 juta & 8,3 juta \\
\hline Jagung & 10,3 juta & 6 juta & 241 ribu \\
\hline Bawang Merah & $588 \mathrm{ribu}$ & $347 \mathrm{ribu}$ & $(65 \mathrm{ribu})$ \\
\hline Bawang Puth & $86 \mathrm{ribu}$ & $151 \mathrm{ribu}$ & $33 \mathrm{ribu}$ \\
\hline Cabai Besar & $311 \mathrm{ribu}$ & $278 \mathrm{ribu}$ & $258 \mathrm{ribu}$ \\
\hline Cabai Rawit & $69 \mathrm{ribu}$ & $327 \mathrm{ribu}$ & $(19 \mathrm{ribu})$ \\
\hline Daging Sapi/Kerbau & $183 \mathrm{ribu}$ & $202 \mathrm{ribu}$ & $219 \mathrm{ribu}$ \\
\hline Daging Ayam Ras & 1,1 juta ton & $881 \mathrm{ribu}$ & $279 \mathrm{ribu}$ \\
\hline Gula Pasir & $987 \mathrm{ribu}$ & $708 \mathrm{ribu}$ & \\
\hline
\end{tabular}

Dari data stok kebutuhan terlihat bahwa adanya penurunan stok kebutuhan memungkinkan akan terjadinya kekurangan pada beberapa komoditas disebabkan karena angka kebutuhan penduduk semakin meningkat. Oleh karenanya dibutuhkan solusi terbaik dalam menjaga tingkat kebutuhan komoditas tersebut, minimal pada beberapa komoditas kita bisa mempersiapkan sendiri guna memenuhi kebutuhan pribadi.

Pada masa pandemik Covid-19 nilai perekonomian masyarakat menurun mengharuskan masyarakat untuk mengambil andil besar dalam ketersediaan kebutuhan secara pribadi pada beberapa komoditas, misalkan cabai, daging ayam, bawang merah dan bawang putih. Beberapa komoditas ini bisa kita tanam pada wilayah dekat rumah dengan menggunakan teknologi pertanian. Selanjutnya apabila tidak terwujudnya program ketahanan pangan maka Indonesia mengalami krisis ketersediaan pangan khususnya pada kota-kota besar. Perlunya mewujudkan ketahanan pangan di Indonesia mendorong banyak komunitas pertanian di kota besar melakukan tindakan pertaniaan di kota besar. Pertanian di kota besar dikenalkan oleh komunitas pertanian yakni Urban Farming. Urban farming memberikan solusi pada hal tersebut dimana pertanian digunakan pada lahan sempit. Konsep pertanian yang menggunakan bahan daur ulang, penggunaan lahan sempit, ada yang menggunakan lahan tanah sempit, ada yang tidak menggunakan lahan tanah menggunakan lahan vertikal, media tanam ada yang menggunakan tanah atau ada yang tidak menggunakan lahan tanah seperti hidroponik, higroponik dan penggunaan jeli tanaman sebagai media tanam.

Urban farming yang berarti bercocok tanam di lingkungan rumah perkotaan dianggap beriringan dengan keinginan masyarakat kota untuk menjalani gaya hidup sehat. Hasil panen dari urban farming lebih menyehatkan lantaran sepenuhnya menerapkan sistem penanaman organik, yang tidak menggunakan pupuk kimia dan pestisida sintesis. Urban farming merupakan strategi pemanfaatan lahan sempit untuk menghasilkan bahan makanan segar sebagai upaya pemenuhan ketersediaan pangan perkotaan dan dapat meningkatkan akses fisik karena sifatnya memperpendek proses distribusi dan dapat meningkatkan akses ekonomi rumah tangga melalui pendapatan rumah tangga. Hamazens dan Meidy (2018) hadirnya aktivitas pertanian perkotaan, dapat mengangkat peran pembangunan pertanian termasuk pembangunan pariwisata melalui aktivitas pertanian di Kota Palu.Inovasi teknologi budidaya pertanian yang dilakukan adalah dengan konsep Urban Farming atau "Kampung Berkebun" diantaranya dengan menggunakan lahan yang bukan tanah, seperti konsep hidroponik, yaitu menanam sayuran dan buah-buahan dengan menggunakan media air, teknik menanam rooftop, vertical garden, menanam di rak vertikultur, di dak rumah, dan tanaman rambat di pergola besi. Jenis sayuran yang ditanam melalui berbagai konsep budidaya tanpa tanah ini memiliki waktu panen singkat, diharapkan setiap bulan panen (R. Mulyani, Heny dan Asep, 2016). 
Bagi kota-kota yang akan menerapkan praktik pertanian perkotaan (urban farming), menurut Fauzi, Annisa dan Heny (2016) sebagai berikut : 1. Memanfaatkan sumberdaya lokal. Oleh karena itu, dalam praktik pertanian perkotaan dapat dijadikan sebagai sarana dalam mengembangkan sumber daya alam khas setempat. 2. Aplikasi teknologi sederhana dan tepat guna yang mudah dilakukan oleh seluruh kalangan masyarakat. 3 . Manfaatkan kembali (reuse) limbah organik kota sebagai sumber hara dan nutrisi bagi tanaman. Sehingga limbah - limbah organik dapat memberikan nilai tambah bagi masyarakat. 4. Praktik pertanian perkotaan diterapkan dengan konsep berkelanjutan dan berwawasan lingkungan. Sehingga dengan adanya konsep seperti itu diharapkan dapat menciptakan lingkungan yang sehat, aman, nyaman, dan bersih. 5. Dukungan pemerintah terhadap pelaku pertanian perkotaan berupa insentif maupun kepastian hukum. Adapun hal yang perlu diperhatikan dalam urban farming adalah adanya kendala atau masalah yang dihadapi masyarakat dalam melakukan pertanian kota kebanyakan secara berurutan adalah terserang hama penyakit tanaman, kekurangan modal untuk mengembangkan, adanya hambatan akibat cuaca ekstrim dan kurangnya pengalaman dan pengetahuan dalam usaha pertanian kota (Parsudi dan Damijanto, 2019).

Berdasarkan keterangan tersebut mengenai permasalahan dan kebutuhan ketersedian pangan serta nilai ekonomis masyarakat maka Urban Farming khususnya pada kota besar untuk menyediakan ketahanan pangan perlu dilakukan dan menjadikan suatu alternatif cara menghasilkan pangan sehingga terwujudnya ketersediaan pangan pada masyarakat Indonesia khususnya di kota besar dapat tercukupi. Inilah yang menjadi acuan kami sebagai tim pengabdi bagaimana melakukan kegiatan pengabdian kami yakni penambah pengetahuan dalam teknologi pertanian. Oleh sebab itu kami melakukan kegiatan pengabdian berupa pemberian informasi dan sharing melalui virtual. Kegiatan dilakukan melalui virtual disebabkan karena keterbatasan jumlah dan permasalah wabah Covid-19 mengharuskan seluruh kegiatan tidak secara fisik dan berkumpul. Dari permasalahan mitra tersebut kami tim pengabdi mengambil kegiatan berupa penanaman tanaman di kota besar atau farming city. Untuk penambah wawasan di lahan sempit di kota besar.

\section{Metode}

Untuk menjawab permasalah yang terjadi pada mitra pengabdi yakni memberikan pengetahuan mengenai pemanfaatan atau pengelolaan lahan pada sekitar rumah tempat tinggal khususnya pada wilayah kota besar dalam mewujudkan nilai ekonomi dan kebutuhan akan pangan di masa pandemik Covid-19 sekarang ini. Maka tim pengabdi melakukan beberapa metode dalam melakukan kegiatan yaitu: 1). Tahap persiapan tim pengabdi sebelum melakukan pengabdian masyarakat yakni pengabdi melihat tingkat kebutuhan mitra, sumber daya yang dapat dimanfaatkan dan penggunaan alat dan bahan yang diperlukan guna memenuhi kebutuhan atas permasalahan yang terjadi pada mitra; 2). Tahap pengabdian, tahap ini tim pengabdi melakukan kegiatan dengan presentasi dan pengenalan urban farming sebagai solusi ketahanan pangan dan nilai ekonomis dengan menggunakan zoom meeting guna memberikan informasi secara langsung dengan tetap menjaga kebersihan diri yang dianjurkan pemerintah pada masa pandemik Covid19; 3). Tahap akhir, evaluasi kegiatan yang telah dilakukan tim pengabdi kepada mitra pengabdi sebagai umpan balik kegiatan.

\section{Hasil dan Pembahasan}

Dari hasil kegiatan pengabdian masyarakat yang telah dilakukan bersama tim pengabdi yang terdiri dari dosen dan mahasiswa. Dimana kegiatan menggunakan media elektronik berupa zoom meeting dengan peserta adalah mahasiswa teknologi pertanian Politeknik Kelapa Sawit Citra Widya Edukasi-Bekasi. Jumlah peserta berjumlah 30 peserta mahasiswa dimana para mahasiswa ini membawa misi atau amanat dari daerah masingmasing tempat mereka (mahasiswa) tinggal karena beberapa mahasiswa dibiayai pemerintah daerah provinsi kalimantan dan beberapa biaya pendidikan secara pribadi. Selanjutnya para pimpinan dari Politeknik Kelapa Sawit Citra Widya EdukasiBekasi berkeinginan bahwa setelah menyelesaikan studi di kampus, mereka bisa membawa pengalaman dan pengetahuan baru yang berkaitan dengan teknologi pertanian yang akan dibawa di wilayah tempat mereka tinggal khususnya pada wilayah kota dan perkampungan di kalimantan. Selain hal tersebut para mahasiswa pun diminta 
supaya bisa berdikari atau berwiraswasta membangun daerah tempat tinggal mereka agar menjadi wilayah yang memiliki perekonomian yang lebih baik dan membuka lapangan pekerjaan baru melalui tangan-tangan muda para alumni.

Dari kondisi dan tujuan lulusan Politeknik Kelapa Sawit Citra Widya Edukasi-Bekasi yang merupakan harapan para dosen yang merupakan pengajar, kepala daerah pada masing-masing tempat tinggal mahasiswa dan para pimpinan Politeknik Kelapa Sawit Citra Widya EdukasiBekasi. Tim pengabdi melakukan kegiatan sebagai berikut:

\section{Melakukan Observasi Awal}

Kegiatan tim pengabdian pertama adalah melakukan observasi awal dengan tujuan agar materi yang diberikan oleh pemateri bisa mengena atau tidak kepada peserta apakah sesuai harapan dan tujuan dari kegiatan yang telah dipersiapkan oleh tim pengabdi. Kegiatan observasi awal yakni menanyakan langsung kepada seluruh peserta dengan 3 pertanyaan : 1. Apakah tujuan dari kalian mengikuti kegiatan zoom meeting dengan tema pertanian "urban farming". 2. Apakah peserta sebelumnya mengetahui "urban farming". 3. Apakah pernah secara langsung menggunakan atau hanya sekedar mencari informasi mengenai "urban farming". Jawaban langsung di jawab pada chat yang disediakan pada platform zoom meeting. Berikut 5 hasil dari jawaban peserta yang diambil secara acak dengan peserta yang sama:

a. Apakah tujuan dari kalian mengikuti kegiatan zoom meeting dengan judul pertanian "urban farming" pada kota-kota besar.

Jawaban peserta : peserta 1. menambah pengetahuan agar dapat digunakan pada tempat tinggal saya. Peserta 2. Cuman pengen ikutan aja. Peserta 3. Saya belum tahu apakah urban farming ini bisa digunakan di daerah saya oleh sebab itu saya ingin tau urban farming ini tuh apa. Peserta 4. Yah cuman ingin ikut doang karena temen-temen sekelas saya yang satu kosan ada yang ikut dari pada sepi. Peserta 5. Semangat ingin tau karena program abdimas sebelumnya yang dilakukan oleh tim pengabdi ini menarik, jadi ingin ikut lagi.

b. Apakah peserta sebelumnya mengetahui "urban farming".

Jawabn peserta : peserta 1. Cuman denger selintas doang pada saat perkuliahan. Peserta 2. Pernah dengar dan belum tau apakah itu. Peserta 3.
Emmmm...belum. Peserta 4. Belum tau. Peserta 5. Pernah denger cuman belum tau pastinya apa.

c. Apakah pernah secara langsung menggunakan atau hanya sekedar mencari informasi mengenai "urban farming".

Jawaban peserta : peserta 1. Belum pernah dan belum cari informasi. Peserta 2. Belum pernah. Peserta 3. Baru mau cari dan buka dari internet informasi urban farming. Peserta 4. Belum pernah. Peserta 5. Belum pernah.

Dari 3 pertanyaan yang telah diberikan tim pengabdi mengambil simpulan awal bahwa peserta ada yang sudah mengetahui dan banyak yang masih belum mengetahui mengenai urban farming. Oleh karenanya tim pengabdi melakukan tindakan kepada pengertian, kebermanfaatan, dan kegiatan urban farming itu sendiri dalam memanfaatkan lahan sekitar pada wilayah perkotaan.

\section{Melakukan Kegiatan Pengabdian Masyarakat Pada Mitra Pengabdi}

Pemberian materi diberikan kepada peserta berupa pemahaman mengenai kegiatan positif yang dapat membantu dalam membuka peluang ekonomi selama pandemik dan ketersediaan pangan melalui urban farming. Kegiatan ini dilakukan hanya pemberian materi oleh pemateri yang dilanjutkan pada kegiatan diskusi interaktif. Berikut foto kegiatan melalui zoom meeting.

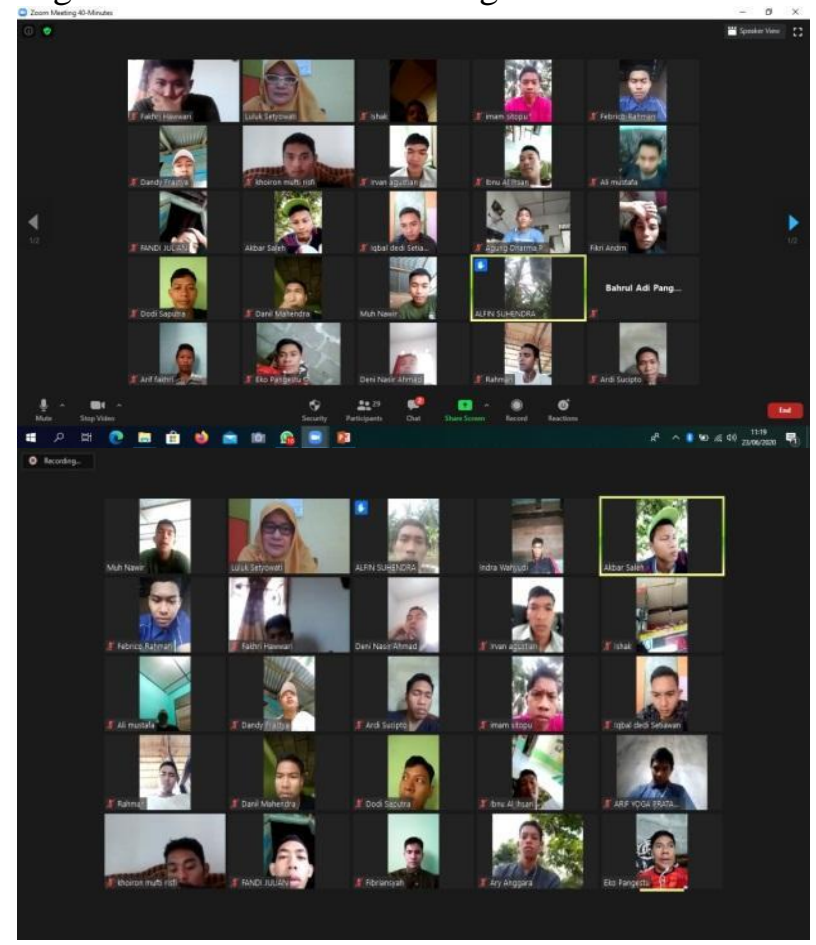




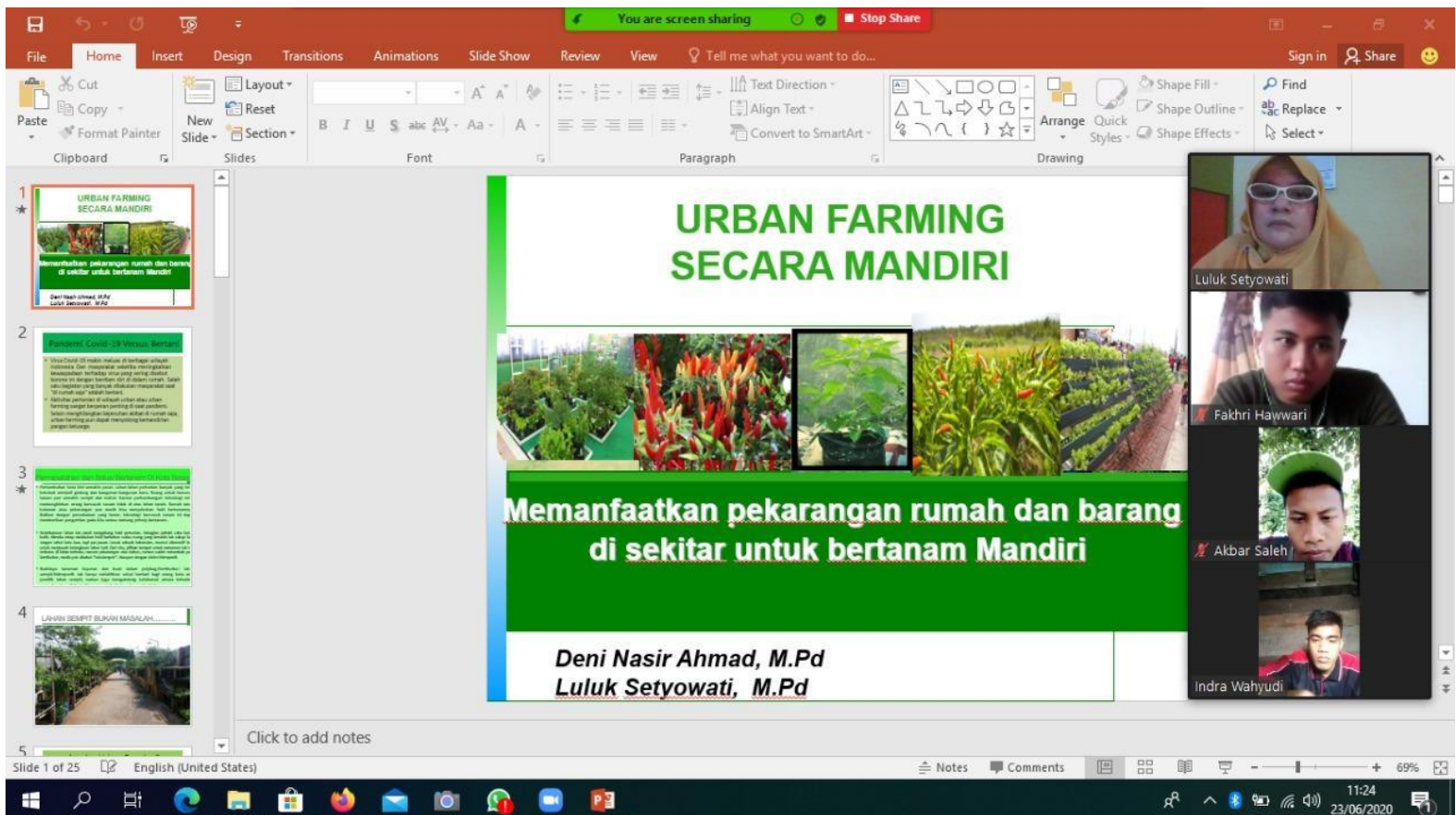

Gambar 1. Foto Kegiatan Dengan Zoom Meeting

Selama jalannya kegiatan pengabdian tim pengabdi memperoleh pertanyaan dari 15 penanya melalui chat zoom meeting yang berkaitan mengenai urban farming dan pertanyaannya miripmirip atau hampir sama dengan pertanyaan pertanyaan peserta lainnya, 5 diantaranya menanyakan sebagai berikut:

a. Apakah memungkinkan bahwa masyarakat perkotaan khususnya masyarakat Jakarta yang memiliki kesibukan yang sangat padat setelah masa pandemi Covid-19 memiliki waktu banyak untuk melakukan kegiatan tanam menanam atau merawat tanaman yang sudah ditanam sebelumnya selama pandemi Covid-19! b. Mungkinkah urban farming menjadi solusi sebagai kegiatan menghilangkan psikologi masyarakat resah terhadap ekonomi mereka!

c. Apakah teknologi hidroponik masuk ke dalam urban farming !

d. Mungkinkah bapak dan ibu pemateri bahwa urban farming bisa dipakai pada pertanian buah besar seperti nangka, durian !

e. Apakah urban farming merupakan solusi ketahanan pangan masyarakat!

Dari 5 pertanyaan yang ditanyakan oleh 15 peserta atau penanya dan hampir mirip - mirip dengan pertanyaan peserta lainnya, maka tim pengabdi mengelompokkan pertanyaan sebagai berikut :

Tabel 2. Mengelompokkan Pertanyaan Berdasarkan Banyak Penanya

\begin{tabular}{|c|l|c|c|}
\hline No & \multicolumn{1}{|c|}{ Pertanyaan } & $\begin{array}{c}\text { Banyak } \\
\text { penanya }\end{array}$ & Persentase \\
\hline 1 & $\begin{array}{l}\text { Kebermanfaatan adanya pertanian urban farming bagi ketahanan pangan dan } \\
\text { ekonomi. }\end{array}$ & 6 penaya & $40 \%$ \\
\hline 2 & Teknologi tepat guna yang dapat dimanfaatkan dalam pertanian urban farming. & 2 penanya & $13,33 \%$ \\
\hline 3 & $\begin{array}{l}\text { Dampak psikologi menanam melalui urban farming bagi masyarakat selama } \\
\text { pendemik Covid-19 }\end{array}$ & 3 penanya & $20 \%$ \\
\hline 4 & $\begin{array}{l}\text { Kemungkinan menanam tanaman buah besar dengan tabulapot atau media } \\
\text { tanam lainnya }\end{array}$ & 2 penanya & $13,33 \%$ \\
\hline 5 & $\begin{array}{l}\text { Apakah masyarakat perkotaan bersedia melakukan atau menanam dengan } \\
\text { "urban farming". }\end{array}$ & 2 penanya & $13,33 \%$ \\
\hline
\end{tabular}




\section{Evaluasi Kegiatan}

Untuk memperoleh hasil dari kegiatan tim pengabdi melakukan evaluasi hasil diantaranya mencari informasi mengenai kebermanfaatan informasi yang telah disampaikan oleh pemateri dan pemahaman peserta mengenai urban farming. Dari hasil evaluasi yang diberikan hampir $85 \%$ telah memperoleh manfaat atas informasi yang telah disampaikan oleh pemateri dan $15 \%$ masih tahap mencari informasi atas kurang manfaat atau belum puas memperoleh informasi yang telah diberikan oleh pemateri berkaitan dengan solusi teknologi yang digunakan pada urban farming di kota besar. Mengenai pemahaman atas informasi berupa ketahanan pangan dan penambahan ekonomi pada masyarakat atau peserta selama pandemik Covid-19 hampir semua peserta telah paham maksud dari urban farming dan bahkan memberikan masukan atau menjadikan sebuah ide pada masing - masing peserta berupa penerapan teknologi terbarukan dalam mengembangkan urban farming pada masyarakat kota besar yang keterbatasan waktu dalam memelihara tanaman komoditas.

\section{Kesimpulan}

Dari hasil kegiatan yang telah dilakukan oleh tim pengabdi bahwa informasi yang telah diberikan oleh pemateri sangat mengena ke peserta atau sesuai dengan kebutuhan informasi bahkan bagi beberapa peserta menjadikan sebuah ide baru berdasarkan permasalahan yang ada dan menjadikan sebuah produk teknologi dalam pertanian. Oleh sebab itu tim pengabdi tidak dapat mengambil kesimpulan yang banyak karena semuanya informasi sudah tim pengabdi berikan tinggal peserta menerima dan merespon atas informasi tersebut.

\section{Daftar Pustaka}

Fauzi, Ahmad Rifqi, Annisa Nur Ichniarsyah, Heny Agustin. 2016. Pertanian Perkotaan : Urgensi, Peranan, Dan Praktik Terbaik Urban Agriculture : Urgency, Role, and Best Practice. Jurnal Agroteknologi, Vol. 10 No. 01 (2016)

Hamzens, Wildani Pingkan S., Meidy Widayanto Moestopo. 2018. Pengembangan Potensi Pertanian Perkotaan Di Kawasan Sungai Palu. Jurnal Pengembangan Kota (2018) Volume 6
No. 1 (75-83) Tersedia online di: http://ejournal2.undip.ac.id/index.php/jpk.

Hirawan, Fajar B., Akita A. Verselita. 2020. Kebijakan Pangan di Masa Pandemi COVID-19. CSIS Commentaries DMRU-048-ID, 14 April 2020. Https://csis.or.id

Parsudi, Setyo, Damaijanto. 2019. Model, Motivasi Dan Kendala Masyarakat Dalam Melakukan Pertanian Kota (Urban Farming) Di Kota Surabaya. AGRIDEVINA : Vol. 8 No.1, Juli 2019

R Mulyani, Henny Sri, Asep Suryana, Dadang Sugiana. 2016. Model Komunikasi Dalam Memasyarakatkan Program Inovasi Urban Farming "Kampung Berkebun" Di Kota Bandung. Edutech, Tahun 15, Vol.15, No.3, Oktober 2016. 